\title{
Effect of $\mathrm{TiH}_{2}$ Particle Size on Aluminum foam Pore Structure
}

\author{
Zhiqiang Guo ${ }^{1, a^{*}}$, Donghui Ma ${ }^{1, b}$, Xiaoguang Yuan ${ }^{1, c}$, Xue Dong ${ }^{2, d}$ \\ ${ }^{1}$ School of Materials Science and Engineering, Shenyang University of Technology, Shenyang \\ 110870, China \\ ${ }^{2}$ Shenyang machine tool Co.LTD, Shenyang 110041, China \\ a guozhiqiang217@163.com, ’261191632@qq.com, 'Yuanxg630121@gmail.com,
}

Keywords: aluminum foam; $\mathrm{TiH}_{2}$ particle size; stability of foaming; pore structure.

Abstract. Pore structures and aluminum foam densities are strongly influenced by the particle size of $\mathrm{TiH}_{2}$ powders. In this paper, TG curves of the the original powders and the 4 kinds of powders which were separaed by the original powders were researched. The foaming process and pore structures using selected $\mathrm{TiH}_{2}$ powders were also systematically researched. The results show that the smaller the particle size of fractions the sooner the particles start to release hydrogen. Big particles have concentrated gas releasing time and high expansion rate, small particles have more stable foaming process. No $2 *(38 \mu \mathrm{m} \sim 48 \mu \mathrm{m})$ with the perfect banlance of hydrogen utilization rate and foaming stability has the optimal pore structure and maximum expansion volume. Pore strctures of precursors using selected $\mathrm{TiH}_{2}$ powders are all better than unseparated ones.

\section{Introduction}

Aluminum foams are porous metallic structures which combine the typical properties of cellular materials with those of metals [1]. The high stiffness-to-mass ratio and good crash energy dissipation ability has led to a variety of applications[2,3]. But up to now the market for aluminum foam is still small[4]. One reason for this is that the available aluminium alloy foams still do not have the required properties, partially owing to the fact that during foaming the evolving cellular structure contains more heterogeneities than would be expected from purely statistical scatter and more than are acceptable in practice[5].

The premature gas release due to the mismatch between the decomposition temperature of the blowing agent (for aluminium alloys mostly $\mathrm{TiH}_{2}$ ) and the melting temperature of the alloy is thought to be a major reason for the inferior cell structure[6]. So researches about the gas releasing process of $\mathrm{TiH}_{2}$ were conducted[7-9]. The onset tempreature of gas releasing is at about $400^{\circ} \mathrm{C}$. The dehydrogenation process as observed by different thermal analyses (in inert atmospheres) is reported to take place in two steps [10-14]. It has been proposed that the first dehydrogenation event is related to hydrogen losses from $\mathrm{Y}-\mathrm{TiH}_{2}$ within its homogeneity range, caused by the transformations of surface hydride species, and that the second and larger endotherm is associated

\section{Experimental}

\section{The experimental materials}

Al powder is the matrix material used in this experiment, $\mathrm{Mg}$ powder is the additive to improve the stability of foams, and $\mathrm{TiH}_{2}$ powder is the foaming agent. Table1 and 2 show the chemical compositions of $\mathrm{Al}$ and $\mathrm{Mg}$ powders.

Table 1 Chemical compositions of aluminum powders

\begin{tabular}{ccllll}
\hline $\mathrm{Al}(\mathrm{wt} \%)$ & paiticle size $(\mathrm{mm})$ & $\mathrm{N}(\mathrm{wt} \%)$ & $\mathrm{Fe}(\mathrm{wt} \%)$ & $\mathrm{Si}(\mathrm{wt} \%)$ & $\mathrm{Cu}(\mathrm{wt} \%)$ \\
\hline$>99.5$ & $0.074-0.15$ & $<0.01$ & $<0.60$ & $<0.30$ & $<0.05$ \\
\hline
\end{tabular}


Table 2 Chemical compositions of magnesium powders

\begin{tabular}{lcllllll}
\hline $\begin{array}{l}\mathrm{Mg}(\mathrm{wt} \%) \\
\mathrm{Cl}(\mathrm{wt} \%)\end{array}$ & paiticle size $(\mathrm{mm})$ & $\mathrm{Al}(\mathrm{wt} \%)$ & $\mathrm{Mn}(\mathrm{wt} \%)$ & $\mathrm{Fe}(\mathrm{wt} \%)$ & $\mathrm{Cu}(\mathrm{wt} \%)$ & $\mathrm{Si}(\mathrm{wt} \%)$ \\
\hline$>99.0$ & $0.074-0.15$ & 0.05 & 0.06 & 0.049 & 0.02 & 0.029 & 0.005 \\
\hline
\end{tabular}

\section{The experimental procedures}

The main purpose of this experiment is to research the influence of particle size of $\mathrm{TiH}_{2}$ to pore structures of aluminum foam that produced by PCM method. So firstly the $\mathrm{TiH}_{2}$ powders were separated into 4 groups by a vibrating screen according to their particle size. And then the 4 groups $\mathrm{TiH}_{2}$ powders with particle range in $48 \mu \mathrm{m} \sim 75 \mu \mathrm{m}, 38 \mu \mathrm{m} \sim 48 \mu \mathrm{m}, 25 \mu \mathrm{m} \sim 38 \mu \mathrm{m}$, and under the $25 \mu \mathrm{m}$ were defined as $1^{*}, 2^{*}, 3^{*}, 4^{*}$. The original powder was defined as $5^{*}$. SEM, Mastersizer2000 laser particle size analyzer were used to analyse the morphology and particle size distribution. The TG curves were also analysed. The next mixing aluminum powder, magnesium powder and the $\mathrm{TiH}_{2}$ powder with 5 different particle sizes respectively. Extruding the mixed metal powder by a YH61-500 $5000 \mathrm{KN}$ metal extruding machine. And heating the extruded precursor to $450^{\circ} \mathrm{C}$ for two hours in the furnace. Then extruding the heated precursor again by an extrusion die with a extrusion ratio of 10:1 to produce the final precursor. Finally the precursor was cutted into small precursors with a size of $\varphi 22$ $\times 20 \mathrm{~mm}$, and then putted the small precursor into the foaming mould for foaming experiment at different temperature.

\section{Results and discussion}

\section{The characteristic of $\mathrm{TiH}_{2}$ powder with different particle sizes}

Table 3 show the particle size distribution and oxygen content of $\mathrm{TiH}_{2}$ powder that was measured by the Mastersizer2000 laser particle size analyzer and EDS after separated by a vibration sieve. It can be found that the vibration sieve efficiently separated the powder in fractions of narrow particle size, and the mean diameter are all in the range of nominal size distribution. And the oxygen content has a tendency to increase with the particle size decreases. Because smaller particles have more larger surface area, and have more greater affinity for oxygen.

Table 3 Particle size distribution of $\mathrm{TiH}_{2}$ powder

Powder Nominal size $(\mu \mathrm{m}) \mathrm{D}_{10}(\mu \mathrm{m}) \quad \mathrm{D}_{50}(\mu \mathrm{m}) \mathrm{D}_{90}(\mu \mathrm{m})$ Mean diameter( $(\mu \mathrm{m})$ Oxygen(wt\%)

\begin{tabular}{llrrrrr}
\hline $1^{*}$ & $48-75$ & 28.2 & 49.7 & 94.9 & 55.4 & 2.53 \\
$2^{*}$ & $38-48$ & 22.3 & 38.5 & 81.5 & 44.5 & 2.73 \\
$3^{*}$ & $25-38$ & 20.8 & 28.3 & 46.5 & 25.7 & 3.39 \\
$4^{*}$ & $\leq 25$ & 4.1 & 12.8 & 26.3 & 19.2 & 4.84 \\
$5^{*}$ & $\leq 75$ & 4.2 & 27.5 & 78.9 & 42.3 & 3.32 \\
\hline
\end{tabular}

Fig 1 show the SEM morphologies of $\mathrm{TiH}_{2}$ powders after separated by the vibrating screen. The particles take on polygonal and have a multi-layered structure, and also have a more homogeneous distribution. The particles of minus 500 meshes(D $\leq 25 \mu \mathrm{m})$ are much more smaller than others.

Fig 2 shows the TG analysis curves of $\mathrm{TiH}_{2}$ powders with different particle size. Three distinct stages are observed in all curves: the stable stage, rapid gas releasing stage and slow gas releasing stage. In first stage, when the temperature falls below a critical value, there is no weight loss. Beyond this value, $\mathrm{TiH}_{2}$ powders rapidly start to release hydrogen, so steep slopes can be found in the second stage. In the last stage, with the temperature increasing, $\mathrm{TiH}_{2}$ weight loss gradually reduced, finally stopped at about $800^{\circ} \mathrm{C}$. The comparison of the 5 curves showed that the smaller the particle size the sooner the particles start to release hydrogen. The start dehydrogenation temperature of the smallest 
particles $(\leq 25 \mu \mathrm{m})$ are about $460^{\circ} \mathrm{C}$. However, the biggest particles are about $520^{\circ} \mathrm{C}$, it' s even closer to the melting point of aluminum alloy. And the powder's toatl wight loss is reduced with the particle size decreases, because of thicker surface oxide acting as barrier to dehydrogenation process. The unseparated $\mathrm{TiH}_{2}$ powder is in the middle of other 4 sizes in both the onset dehydrogenation temperature and weight loss.



Fig 1 SEM morphologies of $\mathrm{TiH}_{2}$ with different particle sizes(a) $48 \mu \mathrm{m} \sim 75 \mu \mathrm{m}$, (b) $38 \mu \mathrm{m} \sim 48 \mu \mathrm{m}$, (c) $25 \mu \mathrm{m} \sim 38 \mu \mathrm{m}$, (d) $\leq 25 \mu \mathrm{m}$

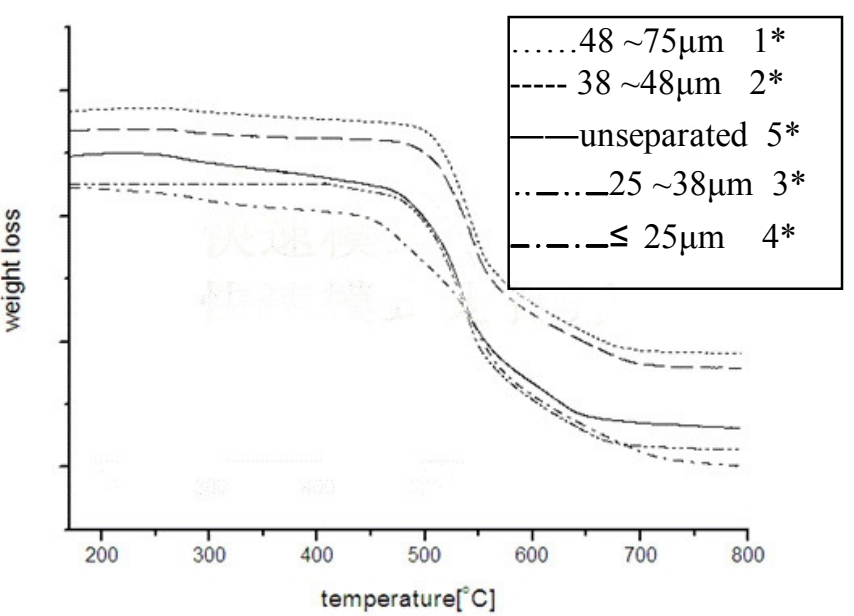

Fig 2 TG analysis curves of different particle size

\section{Effects of $\mathrm{TiH}_{2}$ particle sizes on expansion volume and pore structure}

Fig 3 shows the surface scan maps of Ti element in precursors with different particle sizes. It can be found all kinds $\mathrm{TiH}_{2}$ particles uniformly distributed in precursors, and the extrusion process did not change the particle sizes.

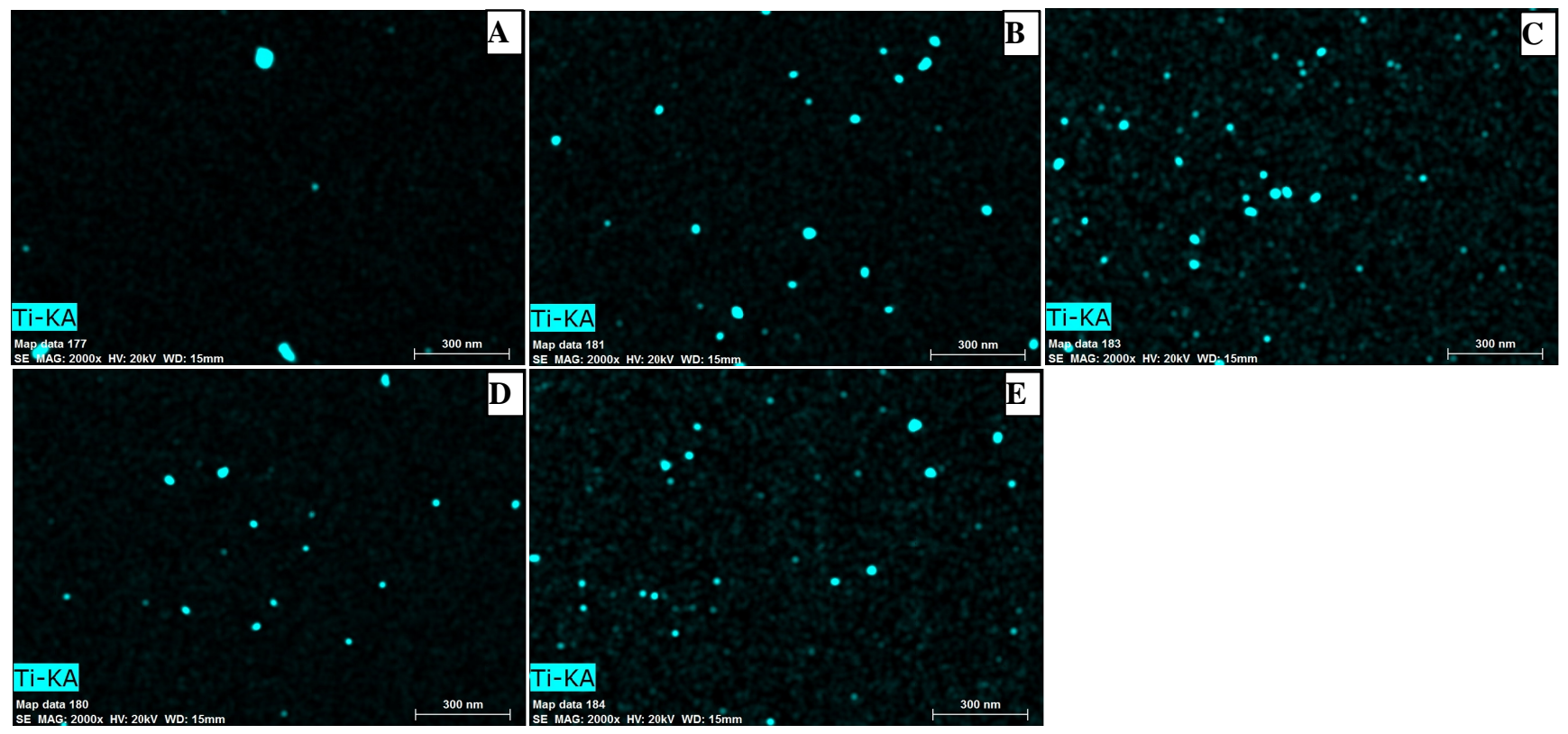

Fig 3 Surface scan maps of Ti element in precursors

(a) $48 \mu \mathrm{m} \sim 75 \mu \mathrm{m}$, (b) $38 \mu \mathrm{m} \sim 48 \mu \mathrm{m}$, (c) $25 \mu \mathrm{m} \sim 38 \mu \mathrm{m}$, (d) $\leq 25 \mu \mathrm{m}$,(e)unseparaed

Fig 4 shows density curves of precursors that using selected $\mathrm{TiH}_{2}$ powders. It can be found all curves showed obvious three stages. Initially, there is an endothermic stage between the precursor and 
the mold walls and heat is transferred via conduction; there is no increase of volume observed at this stage. Once the temperature reached the melting point of aluminum, the precursor softens, a rapid increasing of volume started, untill reaching the maximum value, a significant steep slope of density represents the second stage. Finally, at the last stage, the foams started to break down and the density began increasing. The denstiy curves and $\mathrm{TG}$ curves have similar changing rules, so $\mathrm{TiH}_{2}$ particle sizes must play an important role in foaming process. As Fig 4 shown, the smaller of $\mathrm{TiH}_{2}$ powders the sooner of the starting expansion time, No1* with the biggest particle size is $170 \mathrm{~s}, \mathrm{No} 4 *$ the smallest is $140 \mathrm{~s}$, there is 30 s delaying in foaming. However, there is fast foaming and rapid decay of the big ones; on the contrary, the smaller ones have more stable foaming process. Concentrated gas releasing can effectively improve the utilization rate of hydrogen and reduce the maximum density of alumimum foam, but it also increased the unstability of foaming and deteriorated pore structure. So the particle sizes of $\mathrm{TiH}_{2}$ powders must be controlled within reasonable limits.

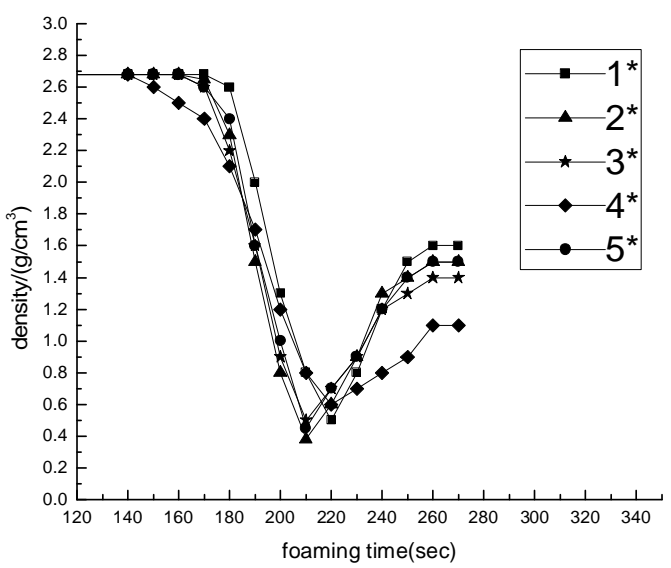

Fig 4 Density curves of precursors that using selected $\mathrm{TiH}_{2}$ powders. $\left(1^{*}\right) 48 \mu \mathrm{m} \sim 75 \mu \mathrm{m},(2 *) 38 \mu \mathrm{m} \sim 48 \mu \mathrm{m}$, $\left(3^{*}\right) 25 \mu \mathrm{m} \sim 38 \mu \mathrm{m},\left(4^{*}\right) \leq 25 \mu \mathrm{m}$, (5*) unseparated



Fig 5 Pore structures of precursors that using selected $\mathrm{TiH}_{2}$ powders. From bottom to top is $1 *$ to $5 *$

Fig. 5 showed pore structures of precursors that using selected $\mathrm{TiH}_{2}$ powders, from bottom to top is from $\mathrm{No}^{*}$ to No5*. It can be found No5* using unseparated $\mathrm{TiH}_{2}$ powders, pore size is not consistent, pore structure is worse, there are many big and through holes exist in precursors. This is caused by the inconsistent of hydrogen releasing time that intensely influenced by the inconsistent $\mathrm{TiH}_{2}$ particle size. Comparing with No5*, pore structures of the other 4 groups are more uniform. Pore diameter decreases with the decreasing of $\mathrm{TiH}_{2}$ particle size. No4* selected the smallest $\mathrm{TiH}_{2}$ powders $(\mathrm{d} \leq 25 \mu \mathrm{m})$ as foming agent has the samllest pore diameter which is not at a level with the other 3 groups, and the expansion volume is also the lowest. From No1* to No3*, pore diameters are all in the same level. However, there is a thick layer of solid aluminum existed in the bottom of No $1^{*}$. because big $\mathrm{TiH}_{2}$ powders have concentrated hydrogen release interval as shown in fig 2 , and high hydrogen utilization. these produced rapid expansion and decay, and a strong drainage effect formed the solid aluminum layer. No2* with the perfect banlance of hydrogen utilization rate and foaming stability has the optimal pore structure and maximum expansion volume. Pore structure of No3* become worse again.

\section{Conclusions}

The particle size of $\mathrm{TiH}_{2}$ powders palys an important role in hydrogen releasing time and pore structures. the smaller the particle size of fractions the sooner the particles start to release hydrogen. $\mathrm{No} 4 *(\leq 25 \mu \mathrm{m})$ the smallest is about $460^{\circ} \mathrm{C}$, No $1^{*}(48 \mu \mathrm{m} \sim 75 \mu \mathrm{m})$ the biggest is about $520^{\circ} \mathrm{C}$, it' $\mathrm{s} 60^{\circ} \mathrm{C}$ 
higher. Big particles have concentrated gas releasing time and high expansion rate, small particles have more stable foaming process. No $2 *(38 \mu \mathrm{m} \sim 48 \mu \mathrm{m})$ with the perfect banlance of hydrogen utilization rate and foaming stability has the optimal pore structure and maximum expansion volume. Pore strctures of precursors using selected $\mathrm{TiH}_{2}$ powders are all better than unseparated ones.

\section{Acknowledgements}

This work was supported by the foundations of Shenyang science and technology plan(F13-078-2-00), and General project of Liaoning Provincial Department of Education(L2013058).

\section{Reference}

1. Banhart, J. Manufacture, characterization and application of cellular metals and metal foams. Prog. Mater. Sci. 2001;46:559-632.

2. J.Banhart, M.F. Ashby, N.A.Fleck. Metal Foams and Porous Metal Structures[A], In: International Conference on Metal Foams and Porous Metal Structures, Bermen, 2003, Verlag MIT, 2006.

3.Liu Jie , Lucai Wang , Wang Fang. The research situation and application prospect of PCM of foam aluminum .[J].Aluminum Processing ,2008,(1):31-34.

4. Lefebvre LP, Banhart J, Dunand DC. Adv Eng Mater 2008,10(9):775.

5. A. Rack, Early pore formation in aluminium foams studied by synchrotron-based microtomography and 3-D image analysis. Acta Materialia 2009, (57) :4809-4821.

6.Banhart J. Metal foam:Production and stability[J].Adv Eng Mater,2006,8(9):781-794.

7.Kennedy A R. The effect of TiH2 heat treatment on gas release and foaming in $\mathrm{Al}-\mathrm{TiH}_{2}$ preforms[J]. Scr Mater,2002,47:763-769.

8.Matijasevic-Lux B, Banhart J, Fiechter S, et al. Modification of titanium hydride for improved aluminium foam manufacture[J]. Acta Mater,2006,54:1887-1893.

9.Gromov A R, Kouznetsova N N, Yudina S L, et al. The investigation of titanium hydride oxidation process[J]. J Alloys Comp,1997,261(1-2):269-276.

10.Zhang Jia-min, Yi Jian-hong, LEI Ting. Dehydrogenation and sintering process of titanium hydride for manufacture titanium and titanium alloy[J]. Technology Review, 2012, 30(1): 65-68.

11.Wang Yao-qi, Zhang Ning, Ren Xue-ping, Hou Hong-liang, Wang Bao-wei. Behavior and rule of titanium hydride dynamic decomposition[J]. Materials Science and Engineering of Powder Metallurgy, 2011, 16(6): 795-798.

12.Eeshova O G, DobrovolskyV D, Solonin Y M, Khyzhun O Y. Hydrogen-sorption and thermodynamic characteristics of mechanically grinded $\mathrm{TiH}_{1.9}$ as studied using thermal desorption spectroscopy[J]. Journal of Alloys and Compounds, 2011, 509: 128-133.

13.Borchers C, Khomenko T I, Leonov A V, Morozova O S. Interrupted thermal desorption of $\mathrm{TiH}_{2}[\mathrm{~J}]$. Thermochimica Acta, 2009, 493: 80-84.

14. P. M. Proa-Flores. G. Mendoza-Suarez. R. A. L. Drew. Effect of $\mathrm{TiH}_{2}$ particle size distribution on aluminum foaming using the powder metallurgy method[J]. J Mater Sci (2012) 47:455-464. 